\title{
EFFECT OF DIABETES AND SCHIZOPHRENIA ON COGNITIVE FUNCTION IN EGYPTIANS
}

\author{
Khaled M. Hadhoud and Amira A. Fouad* \\ Departments of Internal Medicine and Psychiatry* Faculty of Medicine, Zagazig University
}

\begin{abstract}
Background: Cognitive impairment occurs in both schizophrenia (SZ) and diabetes mellitus, in addition, people with SZ are more likely to develop diabetes than those without SZ.

Objective: This study was planned to determine whether SZ patients with diabetes have an increased risk of cognitive impairment than SZ without diabetes or diabetes only.

Subjects \& Methods: The study included 120 subjects, 30 of them were known patients with SZ (Group I), 30 with type 2 diabetes mellitus (T2DM) (group II), 30 of them had SZ with diabetes (Group III) as well as 30 healthy subjects served as control group (Group IV). All subjects were subjected to complete clinical examination, including body mass index [BMI] and waist circumference, in addition to investigations including fasting blood glucose, lipid profile and routine laboratory investigations and assessment of cognitive functions using RBANS [Repeatable Battery for the Assessment of Neuropsychological Status].

Results: SZ with diabetes showed higher fasting blood glucose and triglyceride levels than SZ without diabetes (both P $<0.05$ ). No significant differences between SZ with and without diabetes in duration of illness, antipsychotic types, duration of current antipsychotic treatment (all $\mathrm{P}>0.05$ ). Compared to healthy controls, all patients groups had significantly decreased total and five index RBANS scores [the repeatable pattery for assessment of neuropsychological status] (all $\mathrm{P}<0.01-\mathrm{P}<0.001$ ), except for the visuospatial/ constructional index. SZ with diabetes performed worse than SZ without diabetes in immediate memory $(\mathrm{P}>0.01)$ and total RBANS scores $(\mathrm{P}<0.05)$ and showed a trend for decreased attention $(\mathrm{P}=0.052)$ and visuospatial/constructional capacity $(\mathrm{P}=0.63)$. SZ with diabetes performed worse than diabetes only in immediate memory $(\mathrm{P}<0.001)$ and attention $(\mathrm{P}<0.05)$ and showed a trend for decreased total RBANS scores $(\mathrm{P}=0.069)$.

Conclusion and Recommendations: SZ with Co-morbid diabetes showed more impairment than SZ without diabetes or diabetes only especially in immediate memory \& attention. Thus, diabetes prevention and control should be targeted in patients with SZ.
\end{abstract}

Key words: Schizophrenia, T2DM \& cognitive function.

\section{INTRODUCTION}

$T^{2}$ The incidence of diabetes mellitus (DM) is increasing world wide, and has become an important public health problem(1).

Insulin regulates more than just glucose, it regulates dopamine as well. Lack of dopamine is associated with schizophrenia (SZ) and other maladies such as parkinsonism, social withdrawal and depression(2).

It was found that insulin deficiency or resistance resulted in reduced dopamine and increased nor epinephrine in the prefrontal cortex(2). Compared with the general population, patients with SZ have a higher risk of impaired glucose tolerance and DM(1).

The clinical Antipsychotic Trials of Intervention Effectiveness (GATIE) showed current diabetes in $13 \%$ of schizophrenia participants, and more than $40 \%$ of schizophrenia patients met criteria for the metabolic syndrome (e.g., hypertension, glucose and lipid abnormalities, adiposity)(3). The psychiatric status would be exacerbated when psychiatric patients combined with other diseases (3).

People with schizophrenia may be at increased risk for Type 2 diabetes because of the side effects of antipsychotic medication, poorer overall physical health, less healthy lifestyles, poorer health care(4).
Cognitive impairment in schizophrenia is well defined and has been discovered in many different aspects, including attention, executive functioning, verbal skills, and processing speed(5). Cognitive deficits may represent a core pathophysiological feature of the illness because these deficits are clearly present at the first episode of illness, even in antipsychotic-naive patients $(6,7)$.

Cognitive impairment in diabetes has been found, and most studies showed that obvious cognitive impairment in diabetes patients is relevant to health control groups without $\operatorname{DM}(8,9)$. In addition to the diagnosis and duration of diabetes, prediabetes glucose abnormalities and the metabolic syndrome also have been found to be associated with cognitive impairment(10).

Although these findings demonstrate a relation between diabetes and cognitive performance, studies to examine the association between diabetes and cognitive function in patients with schizophrenia are scarce(11). The aim of the present study was to determine whether schizophrenia patients with diabetes have an increased risk of cognitive impairment or cognitive decline than schizophrenia without diabetes or diabetes only and whether the schizophrenia and diabetes group shows the worst metabolic disorders in comparison to the other studies groups. 


\section{SUBJECTS AND METHODS}

This study was carried out in the Departments of Internal Medicine and Psychiatry, Faculty of Medicine, Zagazig University.

They study was conducted on 120 subjects. They were divided into 4 groups:

\section{(1) Schizophrenia without diabetes (Group I):}

It included 30 known patients with schizophrenia, 19 males and 11 females. The diagnosis was confirmed by the Structured Clinical Interview for DSM. IV (SCID). The duration of the disease was at least 5 years with a mean illness course of $13.1 \pm 8.8$ years. Their ages were between $25-70$ years. The patients were on oral antipsychiatric drugs (as clozapine, risperidone) for at least 1 year prior to entry into the study.

(2) Type 2 diabetes mellitus (T2 DM) with schizophrenia (Group II):

It comprised 30 known patients with T2DM, 18 males \& 12 females with duration of diabetes between 5-10 years with a mean value \pm SD of 7.8 \pm 2.5 , their ages range from $25-70$ years with a mean \pm SD of $(54.1 \pm 8.0)$. All the patients were receiving oral hypoglycemics, mostly metformin and sulphonylurea. No subjects used insulin.

\section{(3) Schizophrenia with T2DM (Group III):}

It comprised 30 patients 18 males, 12 females with matched age, duration of the diseases and lines of treatment as the preceding 2 groups.

\section{(4) Healthy controls (Group IV):}

This group comprised 30 subjects, 18 males and 12 females, matched for age and sex as the diseased groups (with mean age 53.7 \pm 6.08 ).

Patients were recruited from those attending the Diabetes and Psychiatry Clinics of Zagazig University Hospitals.

After being informed on the purpose and procedures of the study, all subjects signed an informed consent form.

Patients that excluded from the study were the patients with any history of diagnosed cerebral vascular disease, coronary heat disease, known neuropsychiatric or central nervous system diseases or any other complications such as nephropathy and retinopathy of T2DM. Since it is known that these cardio-cerebrovascular and central nervous system diseases are associated with cognitive impairments. Also, diabetic retinopathy and nephropathy were strongly linked to impairment in the cognitive domains $(12,13)$ in addition, none of the patients displayed audiovisual or motor coordination impairment that would affect the cognitive function tests.

All patients and control subjects were submitted to full clinical assessment including history taking and thorough clinical examination including body mass index (BMI) and waist circumference and the following investigations:

-Fasting blood glucose.

-Liver function test.

-Blood urea and serum creatinine.

-Urine examination for proteinuria.

-Lipid profile including TG, HDL-C, LDL-C and total cholesterol.

- Fundus examination by ophthalmoscope.

- Plain X - ray (chest \& heart).

-Psychiatric assessment using PANSS [Positive and

Negative Syndrome Scale] (14), in addition to assessment of cognitive function using RBANS [Repeatable Battery for the Assessment of Neuropsychological Status](15).

\section{Blood sampling:}

Venous blood from a forearm vein collected between 7 and 9 am following an overnight fast.

\section{Anthropometric Variables:}

They body weight and height were assessed in a standardized fashion to calculate Body mass index (BMI). Height was measured to the nearest millimeter, with the subjects barefooted and standing upright. Body weight was measured with an electronic scale and subjects were weighed in light indoor clothing. Waist circumference was measured with a measuring tape at a level midway between the lower rib margin and iliac crest with the tape in a horizontal position(16).

Psychometric procedures:

The following scales were administered:

\section{(1) Positive and Negative Syndrome Scales (PANSS)} (Kay et al., 1987):

The PANSS was developed in late 1980s to assess clinical symptoms of schizophrenia(14).

The PANSS includes 30 items on three subscales 7 items covering positive symptoms (e.g., delusions and hallucinations). 7 items covering negative symptoms (e.g., social withdrawal, flat affect, lack of motivation), and 16 items covering general psychopathology (e.g., anxiety, depression). The PANSS was conceived as an operationalized instrument that provides balanced representation of positive and negative symptoms, as well as mood and anxiety symptoms. The PANSS requires a clinician rater because considerable clinical judgment is required. The assessment consists of a semi-structured clinical interview and any available supporting clinical information, such as family member's reports or previous records. The ratings can be completed in $30-40 \mathrm{~min}$. Each item is scored on 10 Rating Scales in Schizophrenia 211 a 7-point Likert scale ranging from 1 to 7 . Therefore, the positive and negative subscales each range from 7 to 49 , and the general psychopathology subscale from 16 to 112 .

(2)The repeatable battery for the assessment of neuropsychological status (RBANS): 
RBANS to to measure cognitive function was utilized(15). The RBANS is composed of 12 subtests that are used to calculate five age-adjusted index scores and a total score(17). Test indices are immediate memory (composed of list learning and story memory tasks); visuospatial/constructional (composed of figure copy and line orientation tasks); language (composed of picture naming and semantic fluency tasks) attention (composed of digit span and coding tasks); and delayed memory (composed of list recall, story recall, figure recall and list recognition tasks).

In this study, the RBANS was translated RBANS into Arabic by a doctor expert in English then presented to 3 professors of psychiatry who accepting it as face validity.

After that, RBANS was applied on 5 healthy medical students then translated it back to English by an expert in English in English center \& compare between the original one \& the one translated back to English. After that, the total score of the Arabic version of the RBANS compared with each part of it to test the internal consistency(40).

Statistical Analysis:

Group comparisons on the demographic and clinical variables used Chi squared or Fisher exact tests for the categorical variables and Student t-tests or analysis of variance (ANOVA) for the continuous variables. The RBANS were analysed using a 2x2 ANOVA representing the between factors of Diagnosis A (schizophrenia vs no schizophrenia) and Diagnosis B (diabetes vs no diabetes). For the RBANS comparisons, we also included age, gender and education as covariates in the multivariate analyses of covariance (MANCOVA). This was to examine significant diagnosis differences across dependent measures from the RBANS total score and its five cognitive domains with the independent predictors being Diagnosis A, Diagnosis B and Diagnosis A multiplied by Diagnosis B interaction. Effect sizes $(<0.1=$ trivial effect, $0.1-0.3=$ small effect, $0.3-0.5$ $=$ medium effect, $>0.5=$ large difference effect) were also calculated for the two-way comparisons and represented the mean difference, in standard deviation units, between the groups of interest. In the post hoc comparisons, a multiple testing correction has also been done. Multiple regression models were used to quantify the amount of variance in cognitive functioning explained by the psychopathological variables after controlling for several potential confounders, such as gender, age, education and clinical variables. SPSS version 18.0 was used to perform all statistical analysis. Data were presented as mean $\pm \mathrm{SD}$. All p-values were two-tailed at the significant level of $<0.05$.

RESULTS

Table (1): Demographic and clinical information of healthy controls, diabetes only, schizophrenia with and without diabetes

\begin{tabular}{|c|c|c|c|c|}
\hline & $\begin{array}{c}\text { (Group I) } \\
\text { Schizophrenia } \\
\text { without diabetes } \\
\end{array}$ & $\begin{array}{c}\text { (Group II) } \\
\text { Diabetes only }\end{array}$ & $\begin{array}{c}\text { (Group III) } \\
\text { Schizophrenia } \\
\text { with diabetes }\end{array}$ & $\begin{array}{l}\text { (Group IV) } \\
\text { Healthy } \\
\text { controls } \\
\end{array}$ \\
\hline Sample size & 30 & 30 & 30 & 30 \\
\hline Sex, male & 63.3 & 60 & $61.80 \%$ & 60 \\
\hline Age (years) & $53.3 \pm 8.3$ & $54.1 \pm 80$ & $54.4 \pm 8.1$ & $53.1 \pm 7.4$ \\
\hline Education (years) & $9.7 \pm 2.4$ & $9.5 \pm 3.4$ & $9.8 \pm 2.5$ & $9.7 \pm 3.0$ \\
\hline Height $(\mathrm{cm})$ & $167.2 \pm 7.0$ & $167.4 \pm 7.9$ & $167.0 \pm 6.8$ & $166.1 \pm 7.6$ \\
\hline Waist (cm) & $92.3 \pm 14.7$ & $93.7 \pm 9.8^{*}$ & $104.8 \pm 10.1 *_{+}$ & $88.0 \pm 10.3$ \\
\hline Hip (cm) & $102.8 \pm 10.0$ & $100.9 \pm 8.5$ & $101.4 \pm 8.5$ & $98.0 \pm 7.2$ \\
\hline Weight (kg) & $69.5 \pm 13.8$ & $72.4 \pm 11.2$ & $78.5 \pm 19.8$ & $71.3 \pm 13.5$ \\
\hline BMI (kg /m2) & $24.9 \pm 4.4$ & $25.8 \pm 3.3$ & $28.0 \pm 6.3$ & $25.7 \pm 3.9$ \\
\hline Fast glucose mg /dl & $95 \pm 0.5++$ & $169.0 \pm 3.2^{*}$ & $110 \pm 1.0++\#$ & $90 \pm 1.4$ \\
\hline Cholesterol gm/dl & $190 \pm 0.9++$ & $220 \pm 2.3$ & $197 \pm 1.0++$ & 130 \\
\hline Triglyceride (mg/d) & $150 \pm 0.8++$ & $250 \pm 6.0$ & $190 \pm 1.4++\#$ & 110 \\
\hline $\begin{array}{l}\text { High density lipoprotein } \\
\text { mg/dl }\end{array}$ & $50 \pm 0.6$ & $45 \pm 0.3$ & $47 \pm 0.2$ & 60 \\
\hline $\begin{array}{l}\text { Low density lipoprotein } \\
\text { mg/dl }\end{array}$ & $120 \pm 0.6$ & $127 \pm 0.9$ & $129 \pm 0.5$ & 90 \\
\hline \multicolumn{5}{|c|}{$\begin{array}{l}\text { Mean }=\mathrm{SD} \\
: \text { Indicates the comparison between healthy and schizophrenia with diabetes or diabetes only. } \\
\mathrm{P}<0.01 . \\
: \text { Indicates the comparison between diabetes only and schizophrenia with or without diabetes: } \\
\mathrm{P}<0.05 \text {. }\end{array}$} \\
\hline
\end{tabular}


$++\mathrm{P}<0.001$.

\#: Indicates the comparison between schizophrenia with and without diabetes.

\#: $\mathrm{P}<001$.

No significant differences among these four examined groups in age, education and gender. Schizophrenia with diabetes had the largest waist circumference. Moreover, Schizophrenia with diabetes showed higher fasting glucose and triglyceride levels than schizophrenia without (both $\mathrm{P}<0.05)$. Compared to healthy controls, diabetes only had larger waist circumferences and fasting

glucose $(\mathrm{P}<0.01)$. In addition diabetes only had higher fasting glucose, triglyceride and cholesterol levels than schizophrenia with and without diabetes $(\mathrm{P}<0.001)$. However, there were no significant differences in height, hip, weight, BMI, high density lipoprotein or low density lipoprotein among four groups (all $\mathrm{P}>0.05$ ).

Table (2): Characteristics of schizophrenia with and without diabetes

\begin{tabular}{lcccc}
\hline & $\begin{array}{c}\text { Schizophrenia } \\
\text { without diabetes }\end{array}$ & $\begin{array}{c}\text { Schizophrenia } \\
\text { with diabetes }\end{array}$ & $\begin{array}{c}\mathbf{t} \text { or } \\
\mathbf{x 2}\end{array}$ & $\begin{array}{c}\text { p- } \\
\text { value }\end{array}$ \\
\hline Duration of illness (years) & $12.4 \pm 7.5$ & $11.6 \pm 9.3$ & -0.32 & 0.750 \\
\hline Antipsychotic types (typicals/ atypicals) & $6 / 24$ & $7 / 23$ & 0.13 & 0.910 \\
\hline $\begin{array}{l}\text { Duration of current antipsychotic treatment } \\
\text { (months) }\end{array}$ & $64.2 \pm 56.3$ & $60.4 \pm 49.3$ & -0.63 & 0.499 \\
\hline Anti parkinsonian drug (yes/no) & $11 / 19$ & $12 / 18$ & 3.74 & 0.053 \\
\hline Score on positive symptoms scale & $13.1 \pm 5.8$ & $12.3 \pm 6.0$ & -0.79 & 0.428 \\
\hline Score on negative symptom scale & $19.9 \pm 6.6$ & $20.8 \pm 7.6$ & 0.83 & 0.408 \\
\hline Score general psychopathology scale & $25.9 \pm 6.3$ & $26.1 \pm 6.2$ & 0.23 & 0.820 \\
\hline Total PANSS score & $58.8 \pm 15.2$ & $59.2 \pm 15.0$ & 0.18 & 0.854 \\
\hline
\end{tabular}

Note: Mean \pm SD

PANSS $=$ Positive and negative syndrome scale

There were no significant differences between schizophrenia with and without diabetes in any PANSS scores, duration of illness, antipsychotic types, duration of current antipsychotic treatment and anti - parkinsonian drug treatment (all $\mathrm{P}>0.05$ ). 
Table (3): The levels of cognitive function in healthy controls, diabetes only, schizophrenia with and without diabetes

\begin{tabular}{|c|c|c|c|c|c|c|c|}
\hline Cognitive & No schi & hrenia & Schizo & hrenia & Diagnosis A & Diagnosis B & Diagnosis A \\
\hline Index & $\begin{array}{l}\text { Healthy } \\
\text { control } \\
(\mathbf{N}=30)\end{array}$ & $\begin{array}{c}\text { Diabetes } \\
\text { only } \\
(\mathbf{N}=\mathbf{3 0})\end{array}$ & $\begin{array}{c}\text { SZ without } \\
\text { diabetes } \\
(\mathbf{N}=\mathbf{3 0})\end{array}$ & $\begin{array}{l}\text { SZ with } \\
\text { diabetes } \\
(\mathrm{N}=30)\end{array}$ & F (P value) & F (P value) & $\begin{array}{l}\text { Diagnosis B } \\
\text { F (P value) }\end{array}$ \\
\hline Immediate memory & $79.6 \pm 28.2$ & $71.6 \pm 15.7$ & $72.0 \pm 19.1$ & $63.2 \pm 14.0$ & $25.4(<0.001) \mathrm{a}$ & $19.6(<0.001) b$ & $0.2(0.693)$ \\
\hline Visuospatial/construction & $86.0 \pm 12.9$ & $85.8 \pm 18.6$ & $89.0 \pm 17.8$ & $84.6 \pm 31$ & $2.4(0.120)$ & $3.2(0.074)$ & $1.2(0.265)$ \\
\hline Language & $97.3 \pm 12.0$ & $90.2 \pm 12.9$ & $89.6 \pm 12.2$ & $88.9 \pm 13.9$ & $7.4(<0.01) \mathrm{a}$ & $5.5(<0.05) \mathrm{b}$ & $9.9(<0.01) \mathrm{c}$ \\
\hline Attention & $89.9 \pm 19.4$ & $88.1 \pm 18.1$ & $85.5 \pm 16.2$ & $80.0 \pm 16.6$ & $16.7(<0.001) \mathrm{a}$ & $10.2(<0.01) b$ & $0.0(0.868)$ \\
\hline Delayed memory & $89.3 \pm 13.5$ & $81.0 \pm 15.0$ & $80.0 \pm 20.3$ & $77.0 \pm 19.6$ & $22.5(<0.001) \mathrm{a}$ & $8.3(<0.01) b$ & $4.7(<0.05) c$ \\
\hline Total RBANS scores & $82.9 \pm 13.1$ & $78.2 \pm 14.0$ & $79.2 \pm 15.8$ & $73.6 \pm 14.1$ & $14.9(<0.001) \mathrm{a}$ & $15.5(<0.001) \mathrm{b}$ & $0.7(<0.388)$ \\
\hline
\end{tabular}

Mean \pm SD. Diagnosis A (Schizophrenia vs no Schizophrenia)

a: There were significant effect on diagnosis A. Diagnosis B (diabetes vs no diabetes)

b: There were significant effect on diagnosis B.

c: There were significant effect on diagnosis A x diagnosis B. 
Compared to healthy controls, nonschizophrenia with diabetes had worse cognitive performance in the immediate memory, language, attention and delayed memory (all $\mathrm{P}<0.01-\mathrm{P}<$ 0.001). Compared to healthy controls, Schizophrenia with and without diabetes had worse cognitive performance in the total RBANS scores and all indices (all $\mathrm{P}<\mathrm{0.001}$ ), except for the visuospatial/constructional index. Schizophernia with diabetes performed worse than non-schizophrenia with diabetes in immediate memory $(\mathrm{P}<0.001)$, and attention $(\mathrm{P}<0.05)$ and they showed a trend to decreases in total RBANS scores $(P=0.069)$. Schizophrenia with diabetes performed worse than schizophrenia without diabetes in immediate memory $(\mathrm{P}<0.01)$ and total RBANS $(<0.05)$. They also showed a trend to decreases in attention $(\mathrm{P}=$ $0.052)$ and visuouspatial /constructional functioning $(\mathrm{P}=0.063)$.

After controlling for age, education and gender, the multivariate analysis of covariance (ANCOVA) revealed statistically significant differences between schizophrenia and no schizophrenia for all cognitive domains $(\mathrm{P}<$ 0.001). Furthermore, diagnosis A (schizophrenia vs no schizophrenia) differences were significant for total RBANS scores and all indices (all $\mathrm{P}<0.01-\mathrm{P}<0.001$ ), except for the visuospatial/constructional index $(\mathrm{P}>0.05)$. Diagnosis $\mathrm{B}$ (diabetes vs no diabetes) had significant effects on total cognitive test scores and all indices (all $\mathrm{P}<$ $0.05-\mathrm{P}<\quad 0.001)$ except for the visuospatial/constructional index $(\mathrm{P}>0.05)$. It was also found that there were significant diagnosis $\mathrm{A} \times$ diagnosis $\mathrm{B}$ effects on language $(\mathrm{P}<0.01)$ and delayed memory $(\mathrm{P}<0.05)$.

\section{DISCUSSION}

Schizophrenia and diabetes are very different issues. Schizophrenia is a mental health condition characterized by periods of psychosis and cognitive impairment. Specifically, memory, reasoning, and cognitive functioning can be significantly impacted by schizophrenia. Even in the absence of psychotic symptoms, these deficits can persist. It has been established that the cognitive impairments in schizophrenia continue throughout the lifetime of a person and do not improve over time (11).

Similarly, diabetes has been shown to be linked to cognitive impairments, especially in the areas of language and memory. Although it is linked to blood glucose levels, lipid counts, and obesity, diabetes has a large effect on mental health. Additionally, people with schizophrenia have nearly double the rate of diabetes than people in the general population(18).

This study examined cognitive function in healthy controls, schizophrenia with and without diabetes and diabetes only. In general, compared to healthy controls all three patient groups displayed significant cognitive impairments. More specifically, schizophrenia with diabetes had worse cognitive functioning than schizophrenia without diabetes and diabetes only. Moreover, we found increased triglyceride levels and waist circumferences that provided significant indication of susceptibility of diabetes for schizophrenia (Table 2).

In our study, we found more significant cognitive impairment in SZ than in healthy control except visouspatial/construction (Table 3). These results are supported by other studies $(19,20,21)$, that have shown that the cognitive impairment in SZ may be associated with abnormalities of brain structure, volume, neurotransmitter receptors, neuronal development and genetic mutations(22-26). However the pathophysiological mechanisms of cognitive impairments in SZ are not completely understood, and deserve further investigations.

Our study indicated that cognitive impairments in diabetes only were present in immediate memory, language, attention and delayed memory (Table 3). This is consistent with other studies(27, 28). Neuropathology and functional neuroimaging studies suggest that cognitive impairments in diabetes may be caused by global and regional dysfunctions of brain energetic metabolism, especially in the hippocampal regions $(29,30)$. Studies have shown that chronic hyperglycemia may cause a significant loss of cortical neurons and reduce the neocortical capillary network, which is associated with cognitive deficits in diabetes(31). Moreover, neuronal glucose malnutrition could cause excessive neuronal pruning in the brain. resulting in cognitive impairment(32). In addition, hyperinsulinemia may inhibit synaptic activity and affect cognitive functioning(32). Taken together, these studies suggest that diabetes may cause significant cognitive deficits.

Importantly, this study found that schizophrenia with diabetes had more serious cognitive deficits than schizophrenia without and diabetes only (Table 3), mainly in immediate memory and attention. These results are consistent with a previous study which found worse cognitive performance across almost all aspects of cognition in schizophrenia with diabetes compared to schizophrenia without diabetes and diabetes only(33).

The discrepancies between our study and that of Dickinson(33) may be due to some factors such as ethinic differences, genetic background, duration of disease. On the other hand, taken together, these results suggest that schizophrenia with diabetes may have additive effects on cognitive deficits, especially on immediate memory \& attention. 
A previous study showed that the neural underpinnings of memory, which are among the most consistent and severe neuropsychological deficits in schizophrenia, are associated with hippocampal activation(34). Abnormalities in the hippocampal brain region may contribute to changes in learning and memory $(35,36)$. Moreover, abnormalities in hippocampal structure and function, which are critically involved in cognitive impairments in learning and memory, are evident across multiple domains among schizophrenia, including brain volume(37). Furthermore, animal studies have shown that diabetes impairs hippocampusdependent memory by reducing dendritic spine density, impairing synaptic plasticity and reducing neurogenesis in the hippocampus(30). Human studies of type 2 diabetes mellitus also found that impaired glucose regulation contributes to hippocampal damage and to impaired memory(38). Interestingly, these memory deficits in schizophrenia may reflect deficiencies in glucose regulation, as a few studies have shown that glucose administration improves these deficits. Other studies have reported increases in verbal declarative memory performance following glucose administration in double-blind crossover designs(39). These studies, together with our finding of impaired immediate memory in schizophrenia with diabetes, support the hypothesis that impaired glucose regulation/availability contributes to the vulnerability for memory deficits in schizophrenia which may be associated with the extensive hippocampal abnormalities in schizophrenia.

In addition, our results showed that the interaction effects of both diagnoses on language and delayed memory were significant, suggesting that both schizophrenia and diabetes could impair the function of language and delayed memory, and produce the synergistic (multiplicative) effects on these cognitive indices.

Thus, these findings provide further evidence of a compounding effect of cognitive erosion for diabetes \& SZ. As SZ with co-morbid diabetes display increased cognitive impairment than both SZ without diabetes and diabetes only, especially in immediate memory and attention, suggesting additive effect of SZ \& diabetes on cognitive deficits.

\section{RECOMMENDATION}

Because people with schizophrenia are more likely than those without to develop diabetes, it is imperative to address risk factors for diabetes as early as possible. Interventions aimed at teaching prevention strategies should be targeted to people with schizophrenia and others most vulnerable to diabetes.

\section{REFERENCES}

1. Dixon L, Weiden P, Delahanty J, et al.: Prevalence and correlates of diabetes in national schizophrenia samples [J]. Schizophr Bull, 2000, 26 (4): 903 912.

2. Michael Siuta and Sabrina Robertson: Dysregulation of the Norepinephrine Transporter sustains Cortical Hypodopaminergia and Schizophrenia. Plos Biology: research article on Diabetes and Schizophrenia, June 21, 2011.

3. Goff DC, Sullivan L M, Mcevoy JP, et al.: A comparison of ten - year cardiac risk estimates in schizophrenia patients from the catie study and matched controls [J]. Schizophr Res, 2005, 80 (1): 45 -53 .

4. Dixon L, Weiden P, Delahanty et al.: Prevalence and correlates of diabetes in national schizophrenia samples. Schizophr Bull, 2000; 26 (4): 903 - 12.

5. Keefe RS, Eesley CE, Poe MP: Defining a cognitive function decrement in schizophrenia $[\mathrm{J}]$. Biol Psychiatry, 2005, 57 (6): 688 - 691.

6. Hill SK, Schuepbach D, Herbener ES, et al..: Pretreatment and longitudinal studies of neuropsychological deficits in antipsychotic - naive patients with schizophrenia [J], Schizophr Res, 2004, 68 (1): 49 - 63.

7. Galderisi S, Davidson M, Kahn RS, et al.: Correlates of cognitive impairment in first episode schizophrenia: the EUFEST study [J]. Schizophr Res, 2009, 115 (2/3): 104 - 114.

8. Pavlik VN, Hyman DJ, Doody R.: Cardiovascular risk factors and cognitive function in adults $30-59$ years of age (NHANES III) [J]. Neuroepidemiology, 2005, 24 (1/2): 42- 50.

9. Arvanitakis Z, Wilson RS, Bienias JL, et al.: Diabetes mellitus and risk of Alzheimer disease and decline in cognitive function $[\mathrm{J}]$. Arch Neurol, 2004, 61 (5): 661 - 666.

10. Yaffe K, Kanaya A, Lindquist $\mathrm{K}$, et al.: The metabolic syndrome, inflammation, and risk of cognitive decline [J]. JAMA, 2004, 292 (18): 2237 - 2242 .

11. Jenwilson: The compound cognitive Impact of schizophrenia and diabetes. Art \& Practice of Psychotherapy, July, 2013.

12. Crosby-Nwaobi R, Sivaprasad S., Forbes A: A systematic review of the association of diabetic retinopathy and cognitive impairment in people with Type 2 Diabetes. Diabetes Research \& Clinical Practice, 2012, 96: 101 - 110.

13. Umegaki H, Limuro S, Shinozaki T, Araki A, Sakurai $\mathrm{T}$, et al.: Risk factors associated with cognitive decline in the elderly with type 2 diabetes: baseline data analysis of Japanese Eldely Diabetes Intervention Trial. Geriatrics \& Gerontology International, 2012, 12 suppl: 1103 109.

14. Kay SR, Fiszbein A, Opter LA: The Positive and Negative Syndrome Scale (PANSS) for schizophrenia. Schizophr Bull, 1987, 13 (2): 261 276. 
15. Randolph C : The Repeatable Battery for the Assessment of Neuropsychological Status (RBANS): Preliminary Clinical Validity. J Clin Exp Neuropsychol; 1998 20: 310 - 9 .

16. World Health Organization: Obesity preventing and managing the global epidemic. In: Organization WH (Ed.), Report a WHO consultation on Obesity, World Health Organization, Geneva 1998, 3 -5.

17. Abe $Y$, Namba $H$, Zheng $Y$, Nawa $H$ : In situ hybridization reveals developmental regulation of Erb B1-4 mRNA expression in mouse midbrain: Implication of ErbB receptors for dopaminergic neurons. Neuroscience 2009, 161: 95 - 110.

18. Yoichiro Takayanagi, Nicola G. Cascella, Akari Sawa et al.: Diabetes is associated with lower global cognitive function in Schizophrenia. Schizophrenia Research, Dec. 2012, vol. 142, issue 1: 183 - 187.

19. Keefe RS: Cognitive deficits in patients with schizophrenia: effects and treatment. J Clin Psychiatry 2007, 68 suppl 148 - 13.

20. Condray R, Yao JK: Cognition, dopamine and bioactive lipids in schizophrenia. Frontiers in Bioscience 2011, 3: 298 - 330.

21. Han M, Huang X - F, Chen DC, Xiu MH, Hui L, et al: Gender differences in cognitive function of patients with chronic schizophrenia. Progress in Neuropsychopharmacology and Biological Psychiatry 2012, 39: 358 - 363.

22. Antonova E., Sharma T., Morris R., Kumari V: The relationship between brain structure and neurocognition in schizophrenia: a selective review. Schizophrenia Research, 2004, 70: 117- 145.

23. Stefansson H. Ophoff RA, Steinberg S, Andreassen OA, Cichon S, et al.: Common variants conferring risk of schizophrenia. Nature 2009, 460: 744- 747.

24. Walters JTR, Corvin A, Owen MJ, Williams H, Dragovic M, et al.: Psychosis susceptibility gene ZNF 804A and cognitive performance in schizophrenia. Archives of general Psychiatry, 2010, 67: 692 - 700.

25. Crook JM, Tomaskovic-Crook E, Copolov DL, Dean B: Decreased muscarinic receptor binding in subjects with schizophrenia: a study of the human hippocampal formation. Biological psychiatry 2000, 48: 381 - 388.

26. Du Bois TM, Deng C, Newell KA, Huang XF: Excitatory and inhibitory neurotransmission is chronically altered following perinatal NMDA receptor blockade. European Neuropsychopharmacology, 2009, 19: 256 - 265.

27. Messier C: Impact of impaired glucose tolerance and type 2 diabetes on cognitive aging. [Review] [33 refs]. Neurobiology of Aging 2005, 1: 26 - 30.
28. Papanikolaou Y, Palmer H, Binns MA, Jenkins Dj, Greenwood CE: Better cognitive performance following a low - glycaemic - index compared with a high - glycaemic - index carbohydrate meal in adults with type 2 diabetes. Diabetologia 2006, 49: $855-862$.

29. Heckers S, Konradi C: Hippocampal pathology in schizophrenia. Current Topics in Behavioral Neurosciences 2010, 4: 529 -553.

30. Stranahan AM, Arumugam TV, Cutler RG. Lee K, Egan JM, et al: Diabetes impairs hippocampal function through glucocorticoid - mediated effects on new and mature neurons, Nature Neuroscience 2008, 11: 309 - 317.

31. Konradi C, Yang CK, Zimmerman El, Lohmann KM, Gresch P, et al: Hippocampal interneurons are abnormal in schizophrenia. Schizophrenia Research, 2011, 131: 165- 173.

32. De Silva PN: Does the association with diabetes say more about schizophrenia and its treatment? - the GLUT hypothesis. Med Hypotheses 2011, 77: 529 531.

33. Dickinson D. Gold JM. Dickerson FB, Medoff D. Dixon LB: Evidence of exacerbated cognitive deficits in schizophrenia patients with comorbid diabetes. Psychosomatics, 2008, 49: 123 - 131.

34. Miller SL. Celone K, Depeau K, Diamond E, Dickerson BC et al.: Age - related memory impairment associated with loss of parietal deactivation but preserved hippocampal activation. Proceedings of the National Academy of Sciences of the United of America 2008, 105: 2181 - 2186.

35. Stone WS, Hsi X: Declarative memory deficits and schizophrenia: Problems and prospects. Neurobiology of learning \& Memory 2011, 96: 544 -552 .

36. Heinrichs RW: The primacy of cognition in schizophrenia. American Psychologist, 2005, 60: $229-242$.

37. Hall J, Whalley HC, Marwick K, McKirdy J, Sussmann J, et al: Hippocampal function in schizophrenia and bipolar disorder. Psychological Medicine 2010, 40: 761 - 770.

38. Convit A: Links between cognitive impairment in insulin resistance: an explanatory model. Neurobiology of Aging 2005, 26 suppl 131 - 35.

39. Sota TL, Heinrichs RW: Sex differences in verbal memory in schizophrenia patients treated with "typical" neuroleptics. Schizophrenia Research 2003, 62: 175-182.

40. Heba A, Rafik A et al., Assessment of cognitive impairment \& neurological soft signs in schizophrenic patients. Thesis, Faculty of Medicine, Zagazig University, 2012. 


\section{دراسة تأثير السكرى والفصام على الوظيفة المعرفية فى المصريين}

قصنور الوظيفة المعرفية يحدث فى كل من مرض الفصام ومرض السكرى، كما أن المرضى المصابون بالفصام أكثر عرضة للإصـابة بمرض السكرى عن من ليس لايهم فصام.

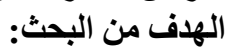

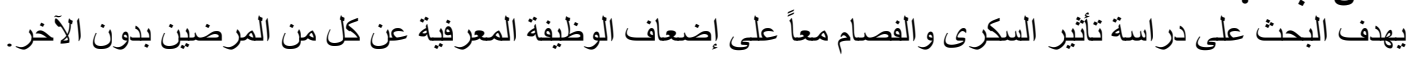
المرضي وطرق البحث:

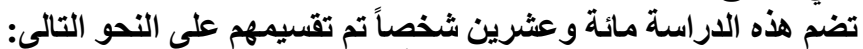

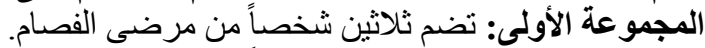

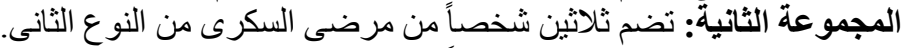

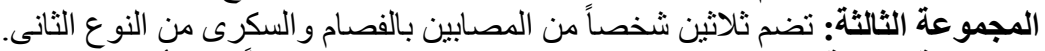

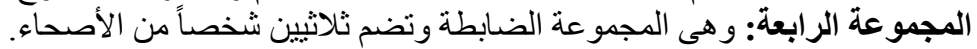

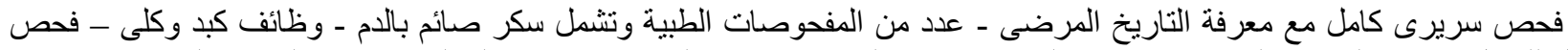
البول للز لال - نسبة الدهون بالدم ـ فحص قاع العين بالإضافة إلى قياس محيط الخصر ومؤشر كتلة الجسم وتقييم الوظيفة المعرفية باستخدام

مقياس RBANS. نتائج البحث: وقا أظهز البحث النتائج الآتية:

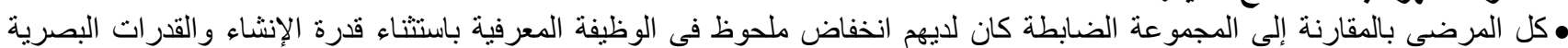

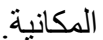
• مرضى الفصام والسكرى معاً كان لديهح تأثر سلبى ملحوظ على الذاكرة القريبة وميل إلى نقص الانتباه والقدرات البصرية المكانية والإنشاء

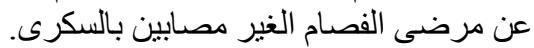
• مرضى الفصام و السكرى معاً كان لديهم تأثثر سلبى على الفير الذاكرة القريبة والانتباه عن مرضى السكرى الغير مصابين بالفصام. وقد خلص البحث إلى أن مرضى الفصام المصابين بالسكرى لايهم قصور فى الوظيفة المعرفية عن مرضى الفصام الغير مصابين

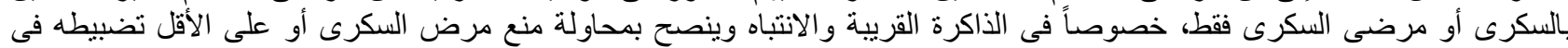
مرضى الفصام لمنع هذا التأثير المزدو فرئ على القدرة المعرفية. 